\title{
A utilização do laboratório de ciências como espaço alternativo para o ensino de ecologia em uma perspectiva ciência-tecnologia-sociedade (cts)
}

The usage of science laboratory as an alternative space to ecology teaching in a science-technology-society perspective

\author{
Mirian Kayser', Leila Cristina Aoyama Barbosa²
}

' Licenciada em Ciências Biológicas (2008) pela Universidade Federal de Santa Catarina e Especialista em Ensino de Ciências (20I2) pelo Instituto Federal de Santa Catarina. Professora Efetiva de Ciências pela Rede Municipal de Ensino de Florianópolis.

${ }^{2}$ Licenciada em Ciências Biológicas (2004) pela Universidade Federal de Mato Grosso, Mestre em Ensino de Ciências (2010) pela Universidade Federal de Mato Grosso do Sul, Doutoranda do Programa de Pós Graduação em Educação Científica e Tecnológica, da Universidade Federal de Santa Catarina. Professora Titular da área de Biologia na Escola

Técnica Estadual de Rondonópolis (MT).

\section{Resumo}

Apesar de ser uma concepção ultrapassada, a educação tradicional ainda impera nos modelos didático-pedagógicos das escolas brasileiras. Uma perspectiva educacional que visa a superação desse modelo é o enfoque Ciência-Tecnologia-Sociedade (CTS) na escola. O objetivo deste trabalho é demonstrar a possibilidade de realização de atividades práticas, sobre ecologia, no ensino fundamental, em perspectiva CTS. Para tanto, esta pesquisa qualitativa, do tipo estudo de caso, teve como público-alvo 44 alunos do $6^{\circ}$ ano do ensino fundamental de uma escola municipal de Florianópolis/SC, com a execução, observação e avaliação de duas atividades práticas, em perspectiva CTS, sobre ecologia. Em relação a atividade prática 1 - "Diário de bordo do desenvolvimento dos fungos" - a maioria dos alunos explicaram o surgimento de fungos no pão devido a anaerobiose e umidade e identificaram a presença de três tipos de fungos. Em relação à atividade prática 2 - "Observação de decomposição da matéria orgânica" - a grande maioria afirmou que a matéria orgânica decomposta pelos fungos pode ser utilizada como um adubo orgânico. Ao fim das duas atividades práticas, a maioria dos alunos concluiu que os fungos são importantes para a indústria alimentícia, farmacêutica e como decompositores de matéria orgânica, demonstrando compreender o tema estudado para além de um conteúdo científico; articulando-o com a tecnologia e a vida em sociedade, objetivos estes da perspectiva CTS.

Palavras Chave: Ensino de Ciências, abordagem CTS no ensino, ensino fundamental.

\begin{abstract}
Despite a outdated conception, the traditional education still rife in the didatic-pedagogic models of brazilian schools. An educational perspective which aims at overcoming the focus of this model is Science-Technology-Society (STS) at school. The objective of this work was to demonstrate the possibility to execute practical activities, about ecology, in the basic education, in STS perspective. For that, this qualitative research, of case study type, had 44 students as target audience, of 6th year of basic education from municipal school to Florianópolis/SC, with execution, observation and assessment of two practical activities, in STS perspective, about ecology. Relative to practice 1 - "Logbook of fungal growth" - most students explained the fungi appearence in the bread due to anaerobiosis and umidity and identified the presence of three fungi types. Relative to practice 2 - "Observation of organic matter decomposition" - most students affirmed that organic matter decomposed by the fungi can be use like organic fertilizer. At the end of two practical activities, most students concluded that fungi are important to food and pharmaceutical industry and how organic matter decomposers, showing understanding the topic studied further than a scientific content; linking it with the tecnology and life in society, these objectives of STS perspective.
\end{abstract}

Keywords: Science education, STS teaching approuch, basic education. 


\section{INTRODUÇÃO}

Vivemos em uma sociedade em que cada vez mais nos deparamos com novos produtos que utilizam novas tecnologias. Além disso, observamos situações e questões sobre avanços científicos e tecnológicos que exigem, de todos nós, novas habilidades e competências. Assim, o Ensino de Ciências torna-se importante na formação escolar do sujeito. Ensinar Ciências propicia o desenvolvimento de várias habilidades e competências. Dentre essas várias habilidades, conforme destaca Guimarães (2009, p. 12) está a possibilidade de compreender as relações entre a ciência e a sociedade, a influência dessa sociedade na produção e na distribuição de diferentes tecnologias.

Entretanto, ainda é possível notar uma forte presença do ensino tradicional na escola. Essa forma de ensino caracterizada por apresentar o conhecimento como algo pronto e definitivo, vai contra a maneira como o conhecimento científico é produzido, já que não leva em conta os aspectos sociais, políticos, históricos e culturais presentes na produção desses conhecimentos. Outro ponto relacionado ao ensino tradicional, é que os ambientes de aprendizagem dessa forma de ensino, segundo Paula (2004, p. 41) "não consideram o conhecimento prévio dos estudantes como ponto de partida no processo de ensino-aprendizagem".

E por vislumbrar que a educação não pode ser meramente mecânica e transmitida, as pesquisas em Ensino de Ciências buscam por metodologias diferenciadas que privilegiem o saber do aluno e as situações de contexto. Dentro dessa perspectiva, várias pesquisas na área da educação abordam a importância da atividade prática, como especificam Morais e Andrade (2010, p. 53 ) ao afirmarem que o desenvolvimento de aulas práticas permitem a aquisição de diversas capacidades cognitivas como: observar, recolher dados, analisar, sintetizar, questionar, entre outras e também "quando bem concebidas e exploradas, essas atividades preparam os alunos para a vida social, para uma cidadania crítica e responsável".

Uma oportunidade para que os indivíduos adquiram essas capacidades e estejam habilitados para compreender assuntos relativos à Ciência e Tecnologia (C\&T) é o Ensino de Ciências ser realizado por meio de discussões sobre as interações da tríade Ciência-Tecnologia-Sociedade (CTS), ou seja, em uma perspectiva CTS. Tal perspectiva é realizada de modo a oferecer ao aluno as condições necessárias para compreender e questionar as tomadas de decisões de questões relacionadas à $\mathrm{C} \& \mathrm{~T}$ que dizem respeito ao coletivo e o torna apto a tomar suas próprias decisões de forma consciente. Os temas escolhidos para serem trabalhados na ótica CTS devem ser aqueles que influenciam o coletivo e estejam conectadas a problemas locais, ou seja, façam parte do contexto do aluno, e tenham como foco, dentre outros, questões relacionadas ao meio ambiente e a saúde.

Desse modo, este artigo apresenta os resultados obtidos em uma situação escolar que articulou atividades práticas em laboratórios de ciências e abordagem CTS para o ensino de ecologia a alunos do $6^{\circ}$ ano do Ensino Fundamental. Trata-se da síntese de um trabalho de conclusão de curso em nível de pós-graduação lato senso ${ }^{1}$ com intuito de divulgar os resultados e manter diálogo com outros professores-pesquisadores deste nível de ensino.

\section{METODOLOGIA}

A pesquisa foi realizada na Escola Básica Municipal João Gonçalves Pinheiro, bairro Rio Tavares, em Florianópolis, com duas turmas de $6^{\circ}$ ano, período vespertino, totalizando 44 alunos, por meio da realização de duas atividades práticas, no Laboratório de Ciências, ao longo do segundo semestre letivo de 2012.

Nessa pesquisa, foram realizadas no Laboratório de Ciências, duas atividades práticas, do campo da Ecologia, em que o conteúdo abordado foi o mesmo: fungos decompositores. As práticas foram realizadas concomitantemente entre si e paralelamente às aulas teóricas sobre o tema, e posteriormente se tornaram objeto de análise dessa pesquisa. As duas atividades práticas foram desenvolvidas com enfoque em CTS.

A sequência didática utilizada nas aulas teóricas foi elaborada a partir de bibliografias especializadas sobre o tema, tanto em relação ao conteúdo que foi trabalhado, quanto a presença da perspectiva CTS em atividades práticas. Essa elaboração aconteceu paralelamente ao desenvolvimento das atividades práticas.

A atividade prática número 1, intitulada "Diário de bordo do desenvolvimento dos fungos" foi desenvolvida ao longo de 4 semanas, totalizando 14 aulas. Essa prática foi adaptada do livro de apoio pedagógico ao professor, Atividades para aulas de ciências, de Guimarães (2009, p. 56).

${ }^{1}$ KAYSER, Mirian. A utilização do Laboratório de Ciências como espaço alternativo para o ensino de ecologia em uma perspectiva CTS, 2012.51f. Monografia, Especialização em Ensino de Ciências, Instituto Federal de Santa Catarina, IF-SC, Florianópolis. 
A atividade prática número 2 , intitulada "Observação de decomposição de matéria orgânica" foi desenvolvida ao longo de 4 semanas, porém, em 4 aulas. Essa prática foi adaptada do livro didático de Barros e Paulino (2009, p. 84).

Para fazer o acompanhamento e, posteriormente, auxiliar na análise dessas atividades práticas foram utilizados dois recursos, baseados em Andrade e Carvalho (2002). O primeiro foi a elaboração de uma ficha de observação, na qual foi anotada as percepções e sensações desta pesquisadora e atitudes, comentários e questionamentos dos alunos após a realização de cada aula. O segundo recurso utilizado foi qualquer documento produzido pelos alunos ao longo do desenvolvimento das atividades práticas. Esses documentos incluem as respostas dos alunos, os desenhos feitos por eles, a pesquisa que realizaram, enfim, materiais por eles produzidos ao longo das atividades práticas. As respostas fornecidas pelos alunos foram tabuladas e analisadas neste trabalho no formato de gráficos.

Com relação à avaliação, a atividade "Diário de bordo do desenvolvimento dos fungos" foi avaliada através da análise dos diários de bordo produzidos pelos alunos. E a atividade "Observação de decomposição de matéria orgânica" foi avaliada através da análise dos relatórios de aula prática também produzidos pelos alunos. Nas duas atividades, além dos instrumentos de avaliação já descritos, foram utilizadas algumas questões que nortearam a pesquisa, tanto no que diz respeito à coleta de dados quanto em sua posterior análise e interpretação, como indicadas: O que leva o aluno a elaborar determinada hipótese? Como chegou a determinada conclusão? De que forma consegue relacionar as hipóteses apresentadas com situações do seu cotidiano? Consegue reconhecer os fungos como um modo de tecnologia? Consegue perceber a relação entre os fungos, a tecnologia e o seu dia a dia? Consegue perceber a relação entre Ciência, Tecnologia e Sociedade?

\section{RESULTADOS E DISCUSSÃO}

A atividade prática 1, "Diário de bordo do desenvolvimento dos fungos" foi a primeira prática realizada. Inicialmente, um pedaço de pão foi cortado em quatro pedaços, umedecido e colocado em um recipiente fechado (isso foi realizado nas duas turmas).

Ao longo de 4 semanas, totalizando 14 aulas, sendo 09 aulas no laboratório, os alunos realizaram suas observações e elaboraram hipóte- ses a respeito do observado. Os alunos, de forma individual, elaboraram o diário de bordo a partir das observações realizadas ao longo do desenvolvimento dos fungos. Os alunos anotaram a data e a hora de cada observação e fizeram um desenho do estágio de desenvolvimento dos fungos sobre o pedaço de pão.

Para essa atividade as perguntas que os alunos responderam foram: 1 - Como ocorreu o aparecimento dos fungos? 2 - Quais condições foram necessárias para o crescimento dos fungos? 3 - Quantos fungos diferentes apareceram nos resultados obtidos pela sala? 4 - Qual é a importância dos fungos encontrados para o meio ambiente? Ao longo das observações os alunos foram orientados a dar suas respostas de acordo com o que já sabiam a respeito do tema, a fazer comparações com situações do seu dia a dia, utilizando assim, seus conhecimentos prévios. As perguntas 1 e 2 foram respondidas ao longo das atividades práticas e novamente após a pesquisa realizada pelos alunos e após a realização da aula teórica (tanto a pesquisa quanto a aula teórica aconteceram após o encerramento da parte prática dessa atividade 1 , na $3^{\text {a }}$ semana).

A pergunta 3 foi respondida apenas durante as atividades práticas e a pergunta 4 foi respondida apenas após a pesquisa realizada pelos alunos e a realização da aula teórica. As perguntas foram propostas aos alunos no segundo dia da atividade prática, após realizarem a primeira observação do pão, portanto, os alunos não sabiam que encontrariam fungos no pão, apenas tinham conhecimento que era uma atividade prática sobre fungos.

Terminada a fase de observação, os alunos realizaram uma pesquisa para coletar dados a respeito das principais características dos fungos e buscar informações sobre sua importância para o ambiente e sua participação na vida dos seres humanos.

A partir da finalização da parte prática, a temática em questão foi trabalhada pela professora através de aulas teóricas. Primeiramente, nessas aulas, foi abordado o Reino Fungi, principalmente as características dos fungos e posteriormente foi apresentado aos alunos como os fungos estão presentes no dia a dia de cada um.

Para isso, foram demonstrados como os fungos podem ser utilizados na área da biotecnologia, sua utilização na indústria alimentícia (exemplo, na fabricação de pães), na produção de medicamentos (exemplo, antibióticos como a penicilina) e outras utilizações nessas áreas.

Todos os dados que foram coletados estão no diário de bordo. Todas as hipóteses levantadas 


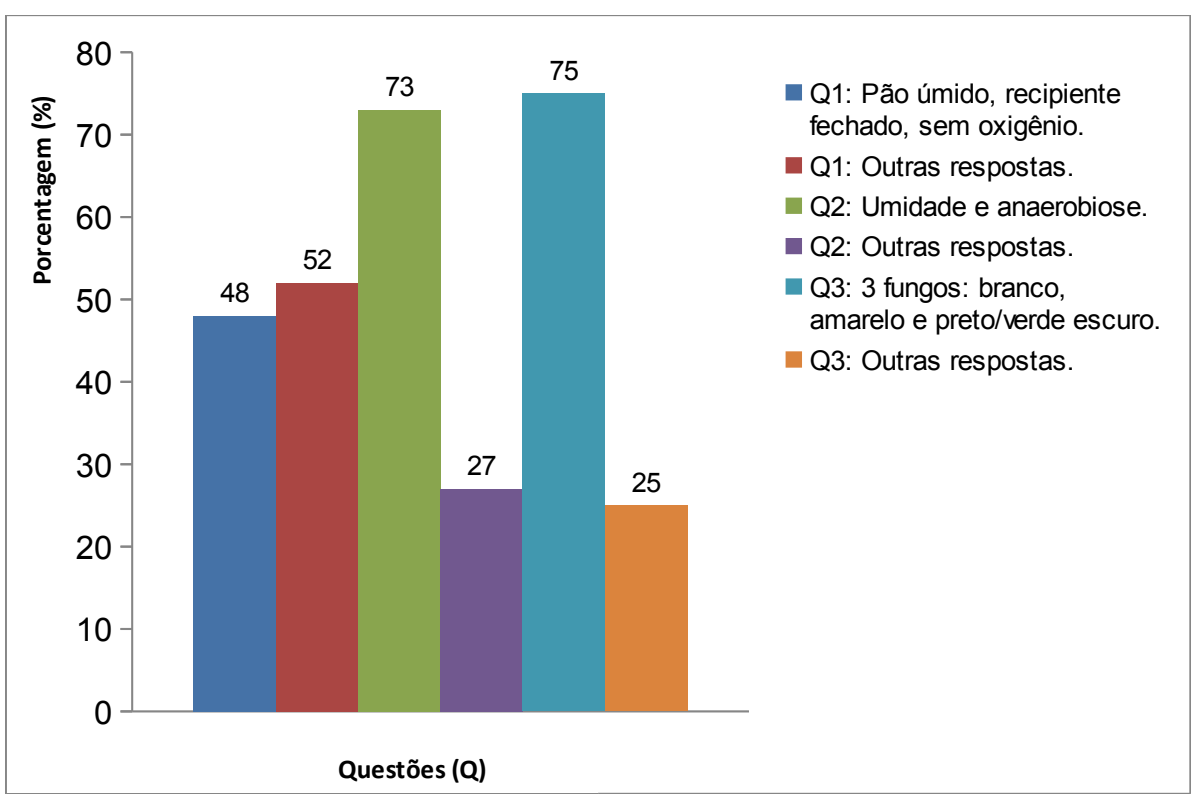

Figura 1: Respostas dos alunos durante a atividade prática (total 44 respostas).

foram avaliadas e, em muitos casos, os alunos reformularam suas respostas, visto que o assunto foi discutido na aula teórica e muitos reconstruíram seus conhecimentos e apresentaram um novo entendimento sobre o assunto. Para finalizar essa primeira atividade, os alunos apresentaram uma conclusão sobre o tema estudado.

As respostas para as questões 1,2 e 3 , produzidas durante a atividade prática, encontram-se na Figura 1:

Das 44 respostas para a questão número 1 , produzidas durante a atividade prática, que mais apareceram, presentes em 21 repostas $(48 \%$ do total), foram relacionadas ao aparecimento dos fungos devido ao pão estar úmido e em um recipiente fechado, sem circulação de ar, portanto, sem a presença do oxigênio. Exemplo de algumas respostas para essa pergunta: "porque o pão estava molhado e sem a entrada do ar", "a umidade fez com que eles aparecessem.

Em relação à questão número $2,73 \%$ dos alunos entendem que os fungos precisam de ambiente úmido e sem oxigênio para se proliferarem. Algumas respostas para essa pergunta: "lugar fechado, sem oxigênio e úmido", "o vidro precisou estar fechado e com um pouco de água" e "sem ar e molhado".

Para responder a essas duas questões, antes da pesquisa feita pelos alunos e das aulas teóricas, os alunos utilizaram os conhecimentos que já possuíam sobre o tema, os conhecimentos ligados a sua cultura, sua família, aos ensinamentos já recebidos na escola em anos passados, sobre o tema. A professora levou em conta, portanto, o conhecimento prévio dos alunos, tanto para produzir o material que seria utilizado nas aulas como para entender e analisar o que levou os alunos a elaborarem determinada hipótese e como relacionaram o que estava acontecendo na atividade prática com situações do seu dia a dia. Essa valorização do conhecimento prévio é destacada por Figueiredo, Messeder e Ramos (2011, p. 68) quando afirmam que as representações prévias transformam algo estranho em familiar, o que possibilita um melhor entendimento do assunto, bem como, afirmam que muitas vezes é mais produtivo para a resolução de uma situação partir do saber prático do que do saber científico.

As respostas para a questão número 3 (total de 44 respostas), produzidas durante as atividades práticas, que mais apareceram, presentes em 33 respostas ( $75 \%$ do total), indicaram que durante a atividade prática, três fungos diferentes foram observados, de coloração amarela, branca e preta ou verde-escuro, conforme a percepção dos alunos. Esse fungos não foram identificados quanto a espécie. Algumas respostas para essa pergunta: "apareceu 3 fungos: um amarelo, um preto e um branco", "dá pra perceber que está com 3 tipos de fungos, um amarelo, um branco e um verde-escuro" e "apareceram 3 tipos de fungos das seguintes cores: amarelados, verde e preto".

Como comentado pela professora durante a realização da atividade prática, as colorações diferentes dos fungos, poderiam indicar que seriam de espécies diferentes. Ao longo de todo o desenvolvimento da atividade prática, os alunos perceberam que não surgiram novas espécies de fungos, apenas que aumentava a quantidade de fungos das 


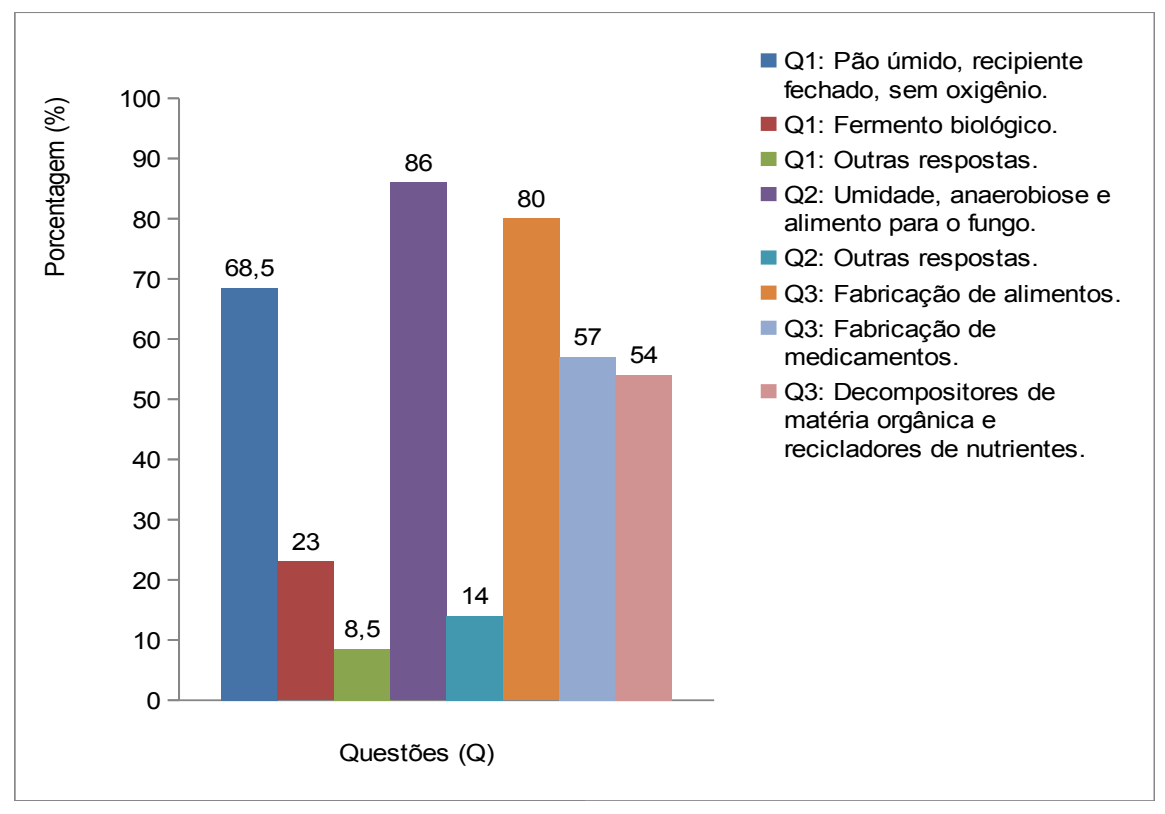

Figura 2: Respostas dos alunos após a pesquisa e aula teórica (total 35 respostas).

três espécies já citadas, como comentou um aluno: "professora, olha, não tem nova espécie de fungo hoje, só tem mais daquele amarelo que tinha na aula passada" $e$ "o pão continua com os três tipos de fungos mas estão bem maiores do que na aula passada e ocupam mais pão".

As respostas para as questões 1, 2 e 4, produzidas após a pesquisa feita pelos alunos e a realização da aula teórica, encontram-se na Figura 2:

As respostas para a questão número 1 (total de 35 respostas, já que nem todos os 44 alunos responderam), produzidas após a pesquisa feita pelos alunos e a realização da aula teórica, que mais apareceram, presentes em 24 respostas $(68,5 \%$ do total), foi a mesma resposta já dada para essa pergunta, que os fungos apareceram devido a umidade e ausência de oxigênio. Apenas poucos registros, cerca de 8 respostas (23\% do total), relacionaram o aparecimento dos fungos, além da umidade e ausência de oxigênio ao fermento biológico (que são fungos) utilizado na fabricação do pão. Algumas respostas para essas perguntas: "o pão foi molhado e colocado dentro de um pote bem fechado. O pão como tem fermento os fungos apareceram, pois dentro do pote estava sem ar", "o fungo apareceu por causa do fermento que já existia na fabricação do pão". Essa hipótese relacionada ao aparecimento dos fungos no pão devido ao fermento biológico presente em sua constituição, não apareceu nas respostas dadas anteriormente, apenas após a realização da aula teórica. Esses alunos fizeram uma relação entre o aparecimento dos fungos e o fermento biológico diferente da que era esperada pela pesquisadora. Em discussões posteriores em sala, essa hipótese foi comentada pela pesquisadora, acredita-se que os alunos tenham percebido que essa hipótese não era correta, por seus comentários e citações, mas não foi realizada uma avaliação escrita para confirmar isso.

Isso indica que a maioria dos alunos, ao formularem suas respostas para a questão número 1 , levaram em conta o fato de o pão ter sido molhado (estava, portanto, úmido) e de estar em um recipiente fechado, sem entrada de oxigênio. Muitos deles, para elaborar suas respostas, fizeram ligação com algumas situações vividas em seu dia a dia, como o comentário feito por um aluno: "professora, lá em casa, quando chove muito, a parede fica mofada, igual esse pão aqui" e outro comentário: "quando um pão fica muito tempo fechado, dentro do saco, ele também fica com fungo, bem esverdeado". Percebe-se que eles entendem que umidade e falta de oxigênio pode levar ao crescimento de fungos.

As respostas para a questão número 2 (total de 35 respostas, já que nem todos os alunos responderam), produzidas após a pesquisa feita pelos alunos e a realização da aula teórica, que mais apareceram, presentes em 30 respostas (86\% do total), indicaram como condições para o crescimento dos fungos a umidade, a anaerobiose e o alimento para os fungos (açúcares do pão). Algumas respostas para essa pergunta: "com a falta de oxigênio, umidade e o pão", "é preciso umidade, falta de ar e alimento para o fungo, que é o pão" e "lugar úmido, fechado e com comida (açúcar do pão)".

Em comparação com as respostas dos alunos antes da realização da experiência e após, identifica-se que ao responderem pela segunda vez, eles acrescentaram como resposta o fator 
"alimento dos fungos". Isso pode estar relacionado com o fato de que, após suas pesquisas e da aula teórica, perceberam as várias formas de nutrição dos fungos, como exemplifica alguns comentários: "professora, os fungos comem matéria orgânica, e o pão é uma matéria orgânica né?!", "os fungos comem matéria orgânica viva, esse pão, a laranja que mofa lá em casa na fruteira e coisas mortas, quando um bicho morre, $e$ ele vai decompor". Isso ratifica a importância do aluno saber pesquisar, de obter as informações que o auxiliem na resolução de um problema (aqui, as perguntas 1 e 2), o que está de acordo com Conrado e El-Hani (2010, p. 4) que afirmam " a capacidade de pesquisar sobre informações relevantes para a resolução de problemas [...] deveriam ser aprendidas no ensino fundamental".

As respostas para a questão número 4 (total de 35 respostas, já que nem todos responderam), produzidas apenas após a pesquisa feita pelos alunos e a realização da aula teórica, que mais apareceram, presentes em 28 respostas $(80 \%$ do total), apresentam como importante a utilização dos fungos na fabricação de alimentos (pães, queijos e bebidas alcoolicas). Outras duas respostas foram bastante observadas nos Diários de bordo, aparecendo em 20 respostas $(57 \%$ do total), a utilização dos fungos na produção de medicamentos (antibióticos como a penicilina) e aparecendo em 19 respostas (54\% do total) os fungos como decompositores da matéria orgânica e recicladores de nutrientes. Algumas respostas para essa pergunta: "para fazer remédios, bebidas, etc. E para decompor a matéria orgânica", "eles ajudam na produção de antibióticos e de alguns alimentos, exemplo: cerveja, pão e queijo" e "alguns fungos ajudam a produzir alimentos. Como por exemplo, o pão. Eoutros ajudam na decomposição".
Em relação a importância dos fungos para o ser humano e o meio ambiente, os alunos conseguiram perceber essa importância. Diferentemente do início da atividade prática, em que alguns alunos falavam dos fungos apenas aspectos negativos, como: "eles são nojentos", " eles estragam meu queijo", "eles mofam as paredes e a comida", após a pesquisa que realizaram e a aula teórica compreenderam que os fungos tem, além do seu aspecto negativo, como provocar doenças no ser humano e em outros seres vivos, muitos aspectos positivos, como demonstram alguns comentários: "os fungos são importantes para a fabricação de queijos", "os fungos são decompositores e devolvem os nutrientes para a terra", "os fungos podem fazer remédios, como o que tomamos pra dor de garganta". Durante a pesquisa, um dos alunos fez um comentário que os demais concordaram, mas sua entonação demonstrou a surpresa ao constatar isso, e seus colegas também, ele disse: "professora, nossa, os fungos são muito importantes! Que irado!" Os alunos, demonstraram com isso, conforme Curtt (2003, p. 26) que fizeram a "interação entre seus entendimentos pessoais do mundo natural (Ciência), com o mundo construído pelo homem (Tecnologia) e as experiências do dia a dia (Sociedade)".

Essas percepções e opiniões dos alunos acerca dos fungos e que traziam também como um conhecimento cultural, foram sendo desconstruídas e reconstruídas pelos alunos com argumentos trazidos pela professora. Analisar e interpretar essas percepções, e não descartá-las ou rotulá-las simplesmente como corretas ou incorretas contribuiu para o aprendizado, e está de acordo com o que é estabelecido em BRASIL (1998, p. 46) em que afirma "reconhecer as noções trazidas pelo aluno, interpretá-las, valorizá-las e combater

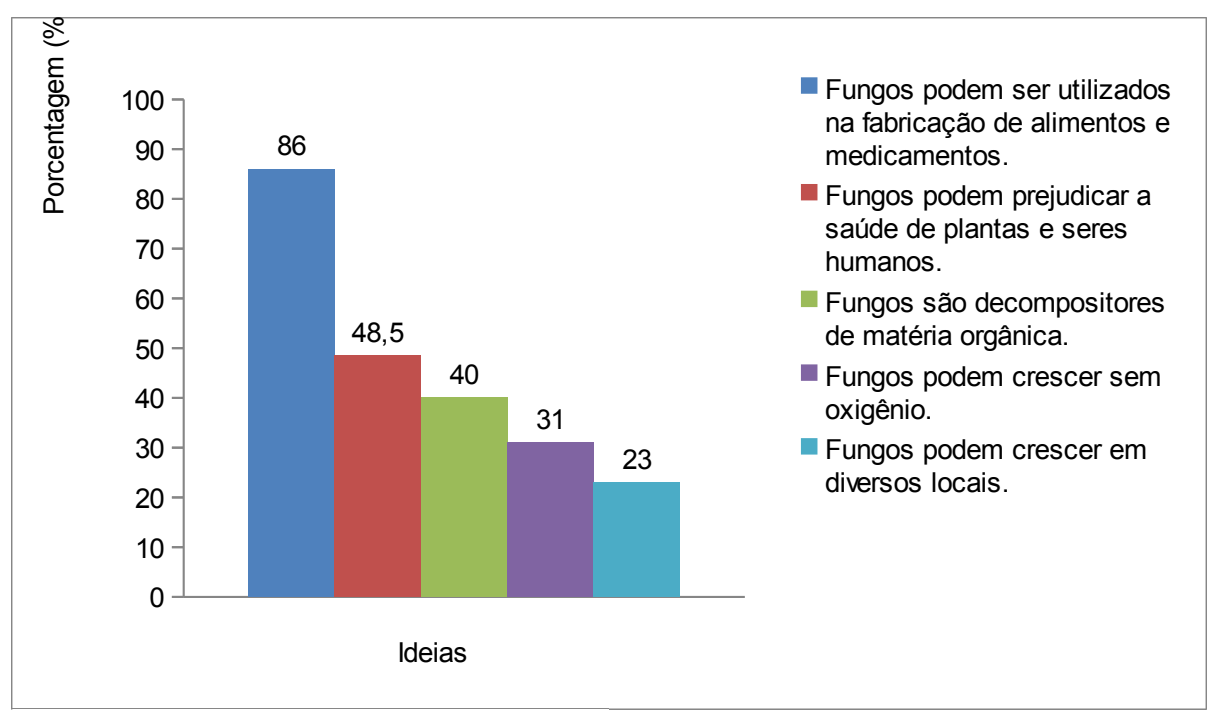

Figura 3: Conclusões dos alunos após a atividade prática (total 35 respostas). 
equívocos graves com argumentos objetivos é parte deste aprendizado".

Nas conclusões apresentadas pelos alunos como finalização da atividade prática 1 , cinco ideias foram amplamente utilizadas pelos alunos. Estas ideias encontram-se na Figura 3:

Acerca das conclusões apresentadas pelos alunos como finalização da atividade prática 1 (total de 35 respostas, já que nem todos os 44 alunos responderam), cinco ideias foram amplamente utilizadas pelos alunos. A conclusão de que os fungos podem ser utilizados na fabricação de alimentos, medicamentos e serem comestíveis apareceu em 30 respostas ( $86 \%$ do total), seguida pela conclusão de que os fungos podem prejudicar a saúde tanto do ser humano como de plantas, apareceu em 17 respostas (48,5\% do total). As outras três ideias não apareceram tantas vezes, mas também merecem destaque, como a que cita os fungos como decompositores de matéria orgânica, apareceu em 14 respostas ( $40 \%$ do total), a que indica que muitos fungos crescem sem presença do gás oxigênio, apareceu em 11 respostas (31\% do total) e por fim, a que menciona onde os fungos podem se desenvolver, como alimentos, paredes e locais úmidos, apareceu em 8 respostas (23\% do total).

Pelas conclusões dos alunos, ficou claro que eles perceberam a importância dos fungos para o ser humano e o meio ambiente, perceberam que os fungos tanto podem ser benéficos como prejudiciais à saúde humana e de outros seres vivos. Algumas expressões que confirmam essa importância que os alunos atribuem aos fungos: "...o pão que nós comemos, não cresceria sem a ajuda dos fungos. Então, sem dúvida, precisamos deles." outra expressão "...são responsáveis por grande parte da decomposição da matéria orgânica, proporcionando a reciclagem de nutrientes".

Essas conclusões também podem ter sido elaboradas observando o que foi apresentado aos alunos durante as aulas teóricas, já que não apenas as características dos fungos foram apresentadas, mas também, ao abordar as utilizações dos fungos pelo ser humano, foi lhes apresentado a Ciência e Tecnologia em um contexto histórico-social, através da história do queijo gorgonzola (em que um fungo é utilizado na sua produção), da história da fabricação de pães (desde a antiguidade até os dias de hoje) e a importância do fermento biológico nesse processo, e, também, da história e do contexto social da descoberta e da propagação durante a $2^{\text {a }}$ Guerra Mundial do primeiro antibiótico, a penicilina.

Esse modo de ensino condiz com uma perspectiva CTS, e é importante pois, segundo Angotti e Auth (2001, p.18) "uma retrospectiva histórica tende a propiciar condições para perceber como chegamos ao estágio atual de desenvolvimento e onde/como as coisas começaram a seguir um certo "caminho".

A atividade prática 1 , na percepção da pesquisadora, promoveu uma participação efetiva do aluno no processo de ensino-aprendizagem e construção do conhecimento. Esse tipo de atividade é muito importante e interessante, na medida em que está de acordo com o que se busca hoje para o Ensino de Ciências, segundo Trogello, Silveira e Danhoni (2012, p. 07). "a utilização de metodologias que propiciem a participação efetiva durante $o$ processo de ensino aprendizagem, que considerem as concepções espontâneas dos alunos, suas falas e seu cotidiano".

Acredita-se que os alunos conseguiram reconhecer os fungos como um modo de tecnologia (por exemplo, para fabricar bebidas alcoólicas e antibióticos). Também acredita-se que os alunos conseguiram perceber a relação entre os fungos, a tecnologia e o seu dia a dia (por exemplo, relacionando com alguns tipos de queijos que consomem em suas casas, o champignon consumido na pizza e a laranja que cai da laranjeira e depois de um tempo apodrece). A pesquisadora supõe que os alunos conseguiram perceber a relação entre Ciência, Tecnologia e Sociedade, tanto pelo que escreveram em suas conclusões, indicando que percebem os fungos ligados a ciência, como um modo de tecnologia e que seus produtos e suas formas de utilização estão presentes na sociedade, em seu dia a dia.

A atividade prática 2, intitulada "Observação de decomposição de matéria orgânica" foi desenvolvida ao longo de 4 semanas, totalizando 4 aulas e utilizando um caixote de madeira $(30 \mathrm{~cm}$ comprimento x $25 \mathrm{~cm}$ largura $\times 15 \mathrm{~cm}$ altura) que foi forrado com plástico e posteriormente preenchido até a metade com terra. Acrescentou-se à terra cascas de frutas, folhas (secas e verdes), borra de café, serragem e cascas de ovos. Misturou-se tudo com uma colher de pau. A caixa foi tampada e deixada em um local que não incidia a luz solar. Quase todos os dias essa mistura foi regada (sem enxarcá-la) e três vezes na semana essa mistura foi revolvida.

A primeira aula realizada sobre essa prática foi apresentar aos alunos a caixa pronta e explicar a eles como a professora havia preparado a caixa. Os alunos foram avisados que após 4 semanas voltariam para observar como havia ficado o material que estava na caixa. Durante esse período, apenas a prática 1 foi sendo desenvolvida. Uma semana 
após a finalização da prática 1 e também após 4 semanas, foram ministradas quatro aulas teóricas sobre adubos orgânicos, agrotóxicos e uma comparação entre eles.

Nessas aulas teóricas foi explicado aos alunos quais as características de um adubo orgânico, como ele é produzido e para que serve. Também foi apresentado aos alunos o conceito de agrotóxicos, e quais as consequências de sua utilização para a saúde humana e meio ambiente. Nesse momento, foram apresentados alguns vídeos sobre os agrotóxicos e seus impactos bem como a história dos agrotóxicos, quando e para qual finalidade foram produzidos e porque posteriormente passaram a ser empregados em plantações.

Após a realização dessas aulas teóricas e a discussão com os alunos sobre o tema, eles foram observar como havia ficado o material que estava dentro da caixa há 4 semanas. Voltando a sala, os alunos se dividiram em duplas (poucos fizeram individualmente) e responderam as seguintes questões: 1 - Qual é o aspecto do material? 2 - Ele tem alguma utilidade? 3 - Explique o que aconteceu. Essas questões constituíram um Relatório de aula prática. Essa prática foi adaptada de Barros e Paulino (2009, p. 84).

As respostas para as questões 1 e 2 encontram-se na Figura 4:

Em relação a questão 1, que trata sobre o aspecto do material, de um total de 21 respostas, a resposta que mais apareceu, em 14 respostas (67\% do total), foi a que declarava que as cascas de frutas estavam pretas e não dava para identificar de qual fruta eram. Algumas expressões que condizem com essa resposta: "não dava para ver as frutas, mas sim, as cascas todas podres e pretas", "as cascas das frutas já estavam pretas" e "as frutas que se encontravam na caixa não dava pra identificar". Outra resposta que também apareceu algumas vezes, em 11 respostas ( $52 \%$ do total), foi relacionada a presença de animais na caixa, como minhocas e formigas. Exemplos dessas expressões: "na caixa tinha animais, tipo: minhoca e formigas", "tinha algumas minhocas lá na caixa" e "dava para ver algumas minhocas e formigas". Outras respostas que apareceram algumas vezes foram a que cita que o material está com um pouco de cheiro ruim, presente em 10 respostas ( $48 \%$ do total) e a que afirma que o material está úmido, presente em 8 respostas ( $38 \%$ do total).

Relativamente a questão 2 , sobre a utilidade desse material, a resposta que mais apareceu, presente em 17 respostas ( $81 \%$ do total), foi que esse material poderia ser utilizado como um adubo orgânico para as plantas. Algumas respostas que comprovam isso: "sim, serve de adubo para outras plantas", "sim, quando plantar, o adubo é melhor para as plantas crescerem" e "para fazer plantações e o adubo tem nutrientes para as plantas crescerem melhor". Outras respostas que apareceram algumas vezes foram que o adubo ajuda as plantas a cresceram saudáveis, observada em 9 respostas ( $43 \%$ do total) e que o adubo também ajuda as plantas a crescerem com mais nutrientes, observada em 4 respostas ( $19 \%$ do total).

Acerca da questão 3, que solicita uma explicação do aluno sobre o que aconteceu com esse material após 4 semanas, em todas as respostas, 21 respostas, com os alunos utilizando diferentes formas para se expressarem, eles afirmaram que os fungos foram decompondo a matéria orgânica. Algumas dessas respostas: " as cascas foram apodrecendo e se decompondo por causa dos fungos e virando adubo orgânico", "aconteceu que as folhas e as cascas

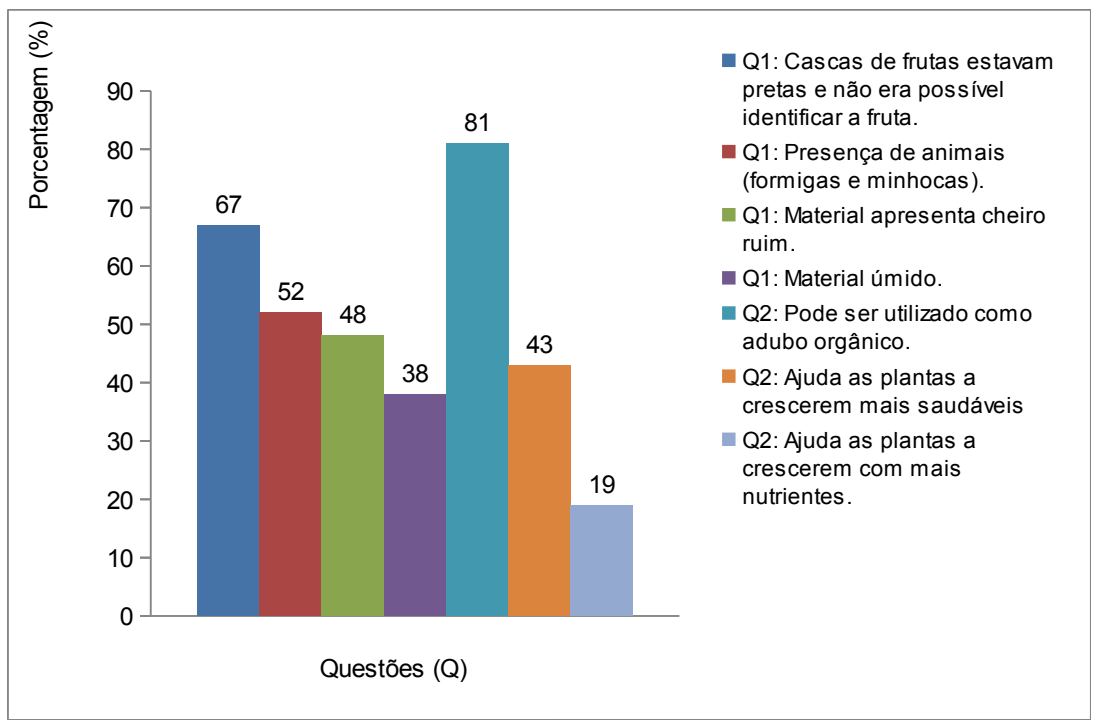

Figura 4: Respostas dos alunos ãs questões da atividade prática 2 (total 21 respostas). 
de frutas se decomporam e viraram adubo (as frutas $e$ as folhas foram decompostas pelos fungos e bactérias)" e "fungos e bactérias comeram os restos de comida e fizeram a decomposição". Outra resposta que também apareceu algumas vezes, foi que os restos de alimento estavam se decompondo e virando adubo (em 5 respostas).

$\mathrm{O}$ que percebe-se com as respostas às 3 questões é que os alunos entenderam o que aconteceu com a matéria orgânica que estava na caixa após 4 semanas. Compreenderam a participação dos fungos decompositores nesse processo, que resultou na decomposição da matéria orgânica e, com isso, a produção de adubo orgânico. Essas respostas também demonstram que os alunos reconheceram as utilizações do adubo orgânico em uma plantação e quais as vantagens para o desenvolvimento da planta dessa utilização.

Também é possível constatar que os alunos, tanto através de suas respostas no relatório como das discussões geradas em sala pelas aulas teóricas e pelos vídeos exibidos, perceberam as vantagens, tanto para a saúde humana como para o meio ambiente, da utilização dos adubos orgânicos em substituição aos agrotóxicos. Alguns comentários feitos pelos alunos durante as aulas que servem para ilustrar esse entendimento: "professora, é claro que é melhor utilizar adubo orgânico", "se é tão perigoso para a saúde, porque ainda utilizam agrotóxicos?", "lá em casa a gente usa adubo orgânico, da composteira que tenho em casa", "prof, aqui na horta (da escola).

Em dois relatórios, nas respostas da questão 2, também argumentaram sobre o benefício da utilização de adubo orgânico em detrimento aos agrotóxicos: "para servir de adubo para outras plantas, para crescerem sem a necessidade de agrotóxicos" e "para dar solo fértil para os vegetais e para não poluir o meio ambiente ao contrário dos agrotóxicos que também prejudicam a saúde". Após a exibição dos vídeos, durante as discussões sobre o tema, os alunos ficaram, de certa forma, espantados ao saberem da história dos agrotóxicos, de que eles foram desenvolvidos para serem utilizados como armas químicas durante a $2^{\mathrm{a}}$ Guerra Mundial e depois passaram a ser utilizados na produção de alimentos. Também comentaram que, começarão a lavar mais suas frutas e verduras e vão pedir aos pais para comprarem produtos sem agrotóxicos, só com adubos orgânicos.

Através da realização destas duas atividades práticas, e da análise dos "Diários de bordo do desenvolvimento dos fungos", dos Relatórios da aula prática, das discussões produzidas em sala e dos comentários feitos pelos alunos, essa pesquisadora confia que os alunos entenderam e aprenderam sobre o Reino Fungi, em especial, os fungos decompositores; porém, através de uma maneira diferente da comumente utilizada em sala de aula. Essas discussões realizadas em sala são essenciais para o desenvolvimento de diversas habilidades dos alunos, como a habilidade de se comunicar, expor suas ideias, aceitar críticas e são também, pertinentes ao Ensino de Ciências, já que promovem uma colaboração entre professor-aluno, aluno-aluno e estão de acordo com uma visão de educação de Silva e Moradillo (2002, p. 8) que afirma que são comportamentos ideais dos alunos " agir socialmente, partilhar seus significados com os colegas e o professor, expor-se à crítica e criticar, falar e ouvir, perguntar e responder, conhecer e valorar tanto o conhecimento aprendido quanto o processo de ensino/aprendizagem".

Apresentar aos alunos um pouco do processo de construção do conhecimento, da produção científica é importante para o processo de ensino e aprendizagem, e se caracteriza como um objetivo fundamental do Ensino de Ciências, como afirmam Silva e Moradillo (2002, p. 7) "ao estudar como os conceitos são construídos e o que explicam, os alunos estão aprendendo como outros aprenderam e podem perceber suas potencialidades, aprender eles mesmos a aprender".

Por meio da realização destas atividades práticas, os alunos também puderam descobrir que por trás de vários produtos que temos hoje na sociedade e que fazem parte de suas vidas (como antibióticos e agrotóxicos) existe uma história, que foi construída conforme a necessidade de cada época, com os valores e costumes das pessoas dessas épocas, com finalidades e objetivos que muitas vezes a maioria de nossos alunos, e de uma grande parcela do restante da sociedade, não conseguem enxergar claramente e, também verificaram que os produtos da Ciência e da Tecnologia, por si sós, não são bons ou maus, o que irá conferir a esses produtos um "rótulo" de bom ou mal, é o uso que se faz deles.

\section{CONSIDERAÇÕES FINAIS}

Pensar no Ensino de Ciências em perspectiva CTS significa que o conteúdo deve ser trabalhado de uma forma contextualizada com a vida do aluno, que relacione situações de seu dia a dia com os conteúdos escolares e o entendimento das ciências como elemento não-neutro e como parte de um processo socio-historicamente desenvolvido (TROGELLO, SILVEIRA, DANHONI, 2012). Portanto, o conhecimento produzido pela ciência 
não é algo definitivo, absoluto e sofre influência de várias formas, como social, cultural, econômica, política e de outras esferas.

Esta investigação buscou desenvolver práticas do ensino de ecologia voltada a uma perspectiva CTS, de maneira a estimular no aluno um pensamento crítico sobre o que é produzido pela Ciência e pela Tecnologia e torná-lo ciente de como esses produtos podem influenciar a sua vida e de toda a sociedade. Também buscou fazer com que os alunos tivessem um papel ativo no processo de ensino-aprendizagem, que construíssem o conhecimento, sozinhos e em colaboração com a professora e com os demais colegas.

Para isso, a elaboração pelos alunos de hipóteses sobre o que estavam observando (na atividade prática 1) e a explicação para o que aconteceu com a matéria orgânica (na atividade prática 2) foi importante para que os alunos praticassem esse papel ativo e se tornassem mais autônomos na busca pelo conhecimento.

Outras estratégias utilizadas para que esse ensino em CTS realmente acontecesse, foi passar vídeos que abordaram a história de alguns produtos da Ciência, os antibióticos e os agrotóxicos, e que tinham relação muito grande com o cotidiano dos alunos. Apresentar esses vídeos aos alunos esclareceu a eles que os produtos que temos hoje passaram por um longo caminho, e por muitos processos e alterações de finalidades, para que se tornassem os produtos que estamos hoje em contato, e também, serviram para mostrar, que assim como as pessoas tem uma história e são influenciadas por suas relações com outras pessoas, assim também são os produtos da Ciência e da Tecnologia, pois apresentam uma história e sofrem vários tipos de influências.

No que concerne a promover o desenvolvimento do senso crítico, de fornecer instrumentos para tomada de decisão a respeito de temas que envolvam a tríade Ciência, Tecnologia e Sociedade, além das estratégias já citadas, as discussões promovidas também foram de grande relevância. Pois fez os alunos refletirem sobre assuntos que ainda não haviam tido a oportunidade de refletir, e também, de incorporar aos seus conhecimentos prévios, novos conhecimentos e novos entendimentos de velhos assuntos.

Desse modo acreditamos que a utilização das atividades práticas em perspectiva CTS tornou o aluno mais autônomo e participativo no processo de aprendizagem, proporcionado a ele a compreensão de que a Ciência é um processo socio-hostoricamente construído, e que os produtos da Ciência e Tecnologia fazem parte do nosso cotidiano e cabe a todos nós, refletirmos sobre esses produtos, desde o processo de produção até suas formas de utilização pela sociedade.

Além disso, um aspecto importante no desenvolvimento deste trabalho foi o processo de construção do professor-pesquisador, que vivencia a sala de aula, busca por maneiras de aperfeiçoar os procedimentos de ensino e reflete sobre os resultados que obtém com suas turmas. Isto se configura como um olhar diferenciado para a educação básica em busca de modelos alternativos de ensino e também no próprio processo formativo do professor que nunca esgota sua formação continuada.

\section{REFERÊNCIAS BIBLIOGRÁFICAS}

ANDRADE, E.C.P; CARVALHO, L.M. O pró-álcool e algumas relações CTS concebidas por alunos de $6^{\mathrm{a}}$ série do ensino fundamental. Ciência \& Educação. v. 8, n. 2, p. 167-185, 2002.

ANGOTTI, J.A.P; AUTH, M.A. Ciência e Tecnologia: implicações sociais e o papel da educação. Ciência \& Educação. v. 7, n. 1, p. 15-27, 2001.

BARROS, C; PAULINO, W. Ciências - o meio ambiente. Ciências $6^{\circ}$ ano. 4. ed. São Paulo: Ática,2009.

BRASIL. Parâmetros Curriculares Nacionais: Ciências Naturais. Brasília: MEC/SEF, 1998, p. 138.

CONRADO, D.M; EL-HANI, C.N. Formação de cidadãos na perspectiva CTS: reflexões para o ensino de Ciências. In: II SIMPÓSIO NACIONAL DE ENSINO DE CIÊNCIA E TECNOLOGIA. 11., 2010, Ponta Grossa. Anais... Ponta Grossa: UTFPR, 2010 ,

CURTT, H.S.S. Artigos de divulgação científica e ensino de ciências: concepções de ciência, tecnologia, sociedade. 2003. 136 f. Dissertação (Mestrado em Educação). Faculdade de Educação. Universidade Estadual de Campinas, Campinas, 2003.

FIGUEIREDO, C.S.M; MESSEDER, J.C; RAMOS, A.C.C. Explorando ciências numa ótica CTS: relato de experiência no ensino fundamental. Ensino de Ciências e Tecnologia. v. 1, n. 1, p. 62 - 69, jan.-jun., 2011.

GUIMARÃES, Luciana R. Atividades para aulas de Ciências: ensino fundamental $6^{\circ}$ ao $9^{\circ}$ ano. Série 
Professor em Ação. 1. ed. São Paulo: Nova Espiral, 2009.

MORAIS, M.B; ANDRADE, M.H.P. Ciências ensinar e aprender: anos iniciais do ensino fundamental. 1. ed. Belo Horizonte: Dimensão, 2010.

PAULA, H. F. A ciência escolar como instrumento para a compreensão da atividade científica. 2004. 364 f. Tese (Doutorado em Educação) - Faculdade de Educação. Universidade Federal de Minas Gerais, Belo Horizonte, 2004.

SILVA, J.L.P.B; MORADILLO, E.F. Avaliação, Ensino e Aprendizagem em Ciências. Ensaio - Pesquisas em Educação em Ciências. v. 04, n. 1, p. 1-12, jul., 2002. 